\title{
Sauropod dinosaur remains from a new Early Jurassic locality in the Central High Atlas of Morocco
}

\author{
Cecily S.C. Nicholl, Philip D. Mannion, and Paul M. Barrett \\ Acta Palaeontologica Polonica 63 (1), 2018: 147-157 doi:https://doi.org/10.4202/app.00425.2017
}

Despite being globally widespread and abundant throughout much of the Mesozoic, the early record of sauropod dinosaur evolution is extremely poor. As such, any new remains can provide significant additions to our understanding of this important radiation. Here, we describe two sauropod middle cervical vertebrae from a new Early Jurassic locality in the Haute Moulouya Basin, Central High Atlas of Morocco. The possession of opisthocoelous centra, a well-developed system of centrodiapophyseal laminae, and the higher elevation of the postzygapophyses relative to the prezygapophyses, all provide strong support for a placement within Sauropoda. Absence of pneumaticity indicates non-neosauropod affinities, and several other features, including a tubercle on the dorsal margin of the prezygapophyses and an anteriorly slanting neural spine, suggest close relationships with various basal eusauropods, such as the Middle Jurassic taxa Jobaria tiguidensis and Patagosaurus fariasi. Phylogenetic analyses also support a position close to the base of Eusauropoda. The vertebrae differ from the only other Early Jurassic African sauropod dinosaurs preserving overlapping remains (the Moroccan Tazoudasaurus naimi and South African Pulanesaura eocollum), as well as stratigraphically younger taxa, although we refrain from erecting a new taxon due to the limited nature of the material. These new specimens represent one of the earliest eusauropod taxa and are an important additional data point for elucidating the early evolution of the clade.

Key words: Dinosauria, Sauropoda, Mesozoic, Gondwana, Morocco, Haute Moulouya Basin.

Cecily S.C. Nicholl [cecily.nicholl14@imperial.ac.uk] and Philip D.

Mannion [philipdmannion@gmail.com], Department of Earth Science and Engineering, Imperial College London, South Kensington Campus, London, SW7

2AZ, UK. Paul M. Barrett [p.barrett@nhm.ac.uk], Department of Earth Sciences, The Natural History Museum, Cromwell Road, London, SW7 5BD, UK. 
This is an open-access article distributed under the terms of the Creative Commons

Attribution License (for details please see creativecommons.org), which permits unrestricted use, distribution, and reproduction in any medium, provided the original author and source are credited.

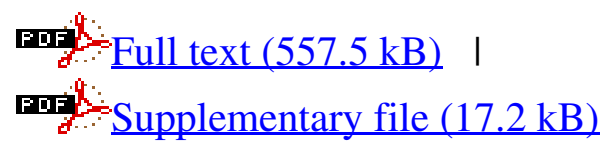

